\title{
Adapting developing country epidemiological assessment techniques to improve the quality of health needs assessments in developed countries
}

\author{
Susan M Smith*1, Jean Long1,2, Jillian Deady¹,3, Frances O'Keeffe1,4, \\ Deirdre Handy ${ }^{1}$ and Tom O'Dowd ${ }^{1}$
}

Address: ${ }^{1}$ Department of Public Health and Primary Care, University of Dublin, Trinity College Centre for Health Sciences, Adelaide and Meath Hospital Dublin, Incorporating the National Children's Hospital, Tallaght, Dublin, Ireland, ${ }^{2}$ Drug Misuse Research Division, Health Research Board, Holbrook House, Holles Street, Dublin, Ireland, ${ }^{3}$ HSE (NA), Westward House, Russell Street, Dublin, Ireland and ${ }^{4}$ Summer Hill Health Centre, Dublin, Ireland

Email: Susan M Smith* - susmith@tcd.ie; Jean Long - jlong@hrb.ie; Jillian Deady - jillian.deady@nahb.ie; Frances O'Keeffe - fokeeffe@campus.ie; Deirdre Handy - dhandy@tcd.ie; Tom O'Dowd - todowd@tcd.ie

* Corresponding author

Published: 29 April 2005

BMC Health Services Research 2005, 5:32 doi:10.1 186/1472-6963-5-32

This article is available from: http://www.biomedcentral.com/l472-6963/5/32

(C) 2005 Smith et al; licensee BioMed Central Ltd.

This is an Open Access article distributed under the terms of the Creative Commons Attribution License (http://creativecommons.org/licenses/by/2.0), which permits unrestricted use, distribution, and reproduction in any medium, provided the original work is properly cited.

\begin{abstract}
Background: We were commissioned to carry out three health assessments in urban areas of Dublin in Ireland. We required an epidemiologically robust method that could collect data rapidly and inexpensively. We were dealing with inadequate health information systems, weak planning data and a history of inadequate recipient involvement in health service planning. These problems had also been identified by researchers carrying out health assessments in developing countries. This paper reports our experience of adapting a cluster survey model originally developed by international organisations to assess community health needs and service coverage in developing countries and applying our adapted model to three urban areas in Dublin, Ireland
\end{abstract}

Methods: We adapted the model to control for socio-economic heterogeneity, to take account of the inadequate population list, to ensure a representative sample and to account for a higher prevalence of degenerative and chronic diseases. We employed formal as well as informal communication methods and adjusted data collection times to maximise participation.

Results: The model we adapted had the capacity to ascertain both health needs and health care delivery needs. The community participated throughout the process and members were trained and employed as data collectors. The assessments have been used by local health boards and nongovernmental agencies to plan and deliver better or additional services.

Conclusion: We were able to carry out high quality health needs assessments in urban areas by adapting and applying a developing country health assessment method. Issues arose relating to health needs assessment as part of the planning cycle and the role of participants in the process.

\section{Background}

In 2001, the Department of Public Health and Primary
Care in Trinity College Dublin was commissioned to carry out three health assessments in urban areas in Dublin. We 
aimed to carry out health assessments that would represent the needs of the whole population and not just more vocal minorities.

We were aware that we were dealing with inadequate health information systems, weak planning data and a history of inadequate recipient involvement in health service planning. International health planners have reported similar issues in developing countries and as a result, have developed appropriate health assessment survey methods. The methods for such surveys must be robust, epidemiologically sound and have the potential to collect data rapidly, inexpensively and simply $[1,2]$. The survey design must provide information at local level and overcome unreliable population lists. If local health care providers and communities can participate in data collection this has the potential advantage of facilitating the meeting of such needs in the local context in due course [3].

To address these issues, a thirty-cluster survey method was designed to carry out health assessments in communities in developing countries $[1,4,5]$. We adapted the thirtycluster survey method and applied it in an urban setting in a developed country. The results of these three health needs assessments have been previously published [6-8] and a summary is provided in Table 1 with reference to online links to the full reports. This paper reports the adaptations made to the thirty-cluster survey method and its implementation to establish the health needs of three urban communities in Dublin, Ireland.

\section{Methods}

\section{Design and setting}

The first two health assessments were commissioned by charitable foundations seeking to support the development of health services in two separate urban areas in Dublin [6,7]. The third assessment [8] was commissioned by a local health board in another area, following the publication of the preliminary results of the first assessment. Each area contained a diverse population though there were higher deprivation levels in the area covered by the first assessment and more elderly people living in the second and third areas studied [6-8].

\section{Adaptations to the original model}

The model was originally designed for use in homogenous populations in developing countries (Figure 1). However, the lack of socioeconomic homogeneity in urban areas in developed countries had to be considered in the selection of the study population. Detailed descriptions of the areas covered, including maps, and the slight variation in demographic characteristics in participants in each area are presented in the individual reports [6-8]. The Small Area Health Research Unit has calculated depriva- tion scores for all of the electoral divisions in Ireland, including the three areas surveyed (full details provided in section 2.1 of the Tallaght report [6]). These deprivation scores, based on data from the 1996 census, range from one to five depending on the level of deprivation. For each of the three areas surveyed, the deprivation scores were aggregated to form less deprived and more deprived groupings and separate samples were selected from each grouping [9]. The adaptations we made are summarized in Figure 2.

In developing countries, people are informed about surveys through community leaders and by word of mouth. We also used more formal methods, such as mailshots, posters at health and social care facilities, and advertisements in the local paper and on radio. Early on in the first survey, when many of the survey letters were returned unopened due to the high turnover of households in urban areas, we changed the addressee on survey envelopes to 'householder', giving us a response rate of at least $76 \%$ for each survey. In the second assessment, in a docklands regeneration area, access to households was difficult due to high security gates in apartment complexes, which was not considered prior to designing the survey.

\section{Results \\ Health needs versus health service needs}

The model we adapted had the capacity to incorporate health needs in the broadest sense as well as identify health service needs, and demonstrated the importance of community-based approaches to public health. The international shift to evidence based medicine has been criticised as removing the focus from the social and environmental determinants of health [10]. Some of our survey findings related to the broad determinants of health, such as the need for social outlets for teenagers and security systems for the elderly. This emphasizes the need for a multi-sectoral approach to the health of communities and stresses the importance of collecting truly representative views that reflect the social components of health. The fears expressed about personal safety led to an increased police presence on the street in one of the areas. The second assessment [7], was used by community activists to lobby the funding charity involved, to provide a bus service to transport older residents to the day centre. This focus on the broader determinants of health has also been reported in other health assessments with the development of new bus routes following such a survey in Edinburgh [11].

The reports highlight the potential discrepancy between communities' expectations of services and actual service provided as there was in fact quite high prevalence of use of hospital services. These discrepancies could be further explored using a qualitative approach. The addition of a 
Table I: Summary of aims and main results of the Health Needs Assessments carried out. Full reports can be downloaded from: http:/ Iwww.tcd.ie/Community Health [see reference list for individual report links]

\begin{tabular}{|c|c|c|c|}
\hline & Tallaght & Finglas & Docklands \\
\hline & \multicolumn{3}{|c|}{$\%(95 \% \mathrm{Cl} *)$} \\
\hline Aims & \multicolumn{3}{|c|}{$\begin{array}{l}\text { to assess the health needs of households and their individual members } \\
\text { residing in each of the three areas surveyed }\end{array}$} \\
\hline Sample size & $\begin{array}{l}420 \text { households } \\
1313 \text { individuals }\end{array}$ & $\begin{array}{l}420 \text { households } \\
963 \text { individuals }\end{array}$ & $\begin{array}{l}360 \text { households } \\
699 \text { individuals }\end{array}$ \\
\hline Response rate & $80 \%$ & $77 \%$ & $75 \%$ \\
\hline $\begin{array}{l}\text { Proportion with a chronic illness (cardiovascular and respiratory } \\
\text { disease and arthritis most common) at the time of the survey }\end{array}$ & $22 \%(19 \%-24 \%)$ & $31 \%(28 \%-34 \%)$ & $27 \%(22 \%-31 \%)$ \\
\hline Proportion with disability at the time of the survey & $3 \%(2 \%-4 \%)$ & $4 \%(3 \%-6 \%)$ & $3 \%(2 \%-4 \%)$ \\
\hline \multicolumn{4}{|l|}{ Psychosocial issues: } \\
\hline Experienced 'stress' in the 12 months prior to the survey & $59 \%(54 \%-65 \%)$ & $63 \%(57 \%-69 \%)$ & $53 \%(47 \%-59 \%)$ \\
\hline Experienced violence in the 12 months prior to the survey & $10 \%(7 \%-13 \%)$ & $13 \%(9 \%-17 \%)$ & $11 \%(7 \%-15 \%)$ \\
\hline Anxiety re: teenagers in household & $60 \%(53 \%-66 \%)$ & $61 \%(49 \%-73 \%)$ & $64 \%(47 \%-81 \%)$ \\
\hline Problem with drugs/ alcohol & $2 \%(1 \%-3 \%)$ & $1 \%(0.4 \%-2 \%)$ & $1 \%(0.1 \%-3 \%)$ \\
\hline Current smokers at the time of the survey & $40 \%(36 \%-45 \%)$ & $28 \%(24 \%-31 \%)$ & $32 \%(27 \%-38 \%)$ \\
\hline \multicolumn{4}{|l|}{ Womens' Health: } \\
\hline Using family planning method at the time of the survey & $56 \%(48 \%-64 \%)$ & $51 \%(41 \%-60 \%)$ & $46 \%(36 \%-56 \%)$ \\
\hline Cervical smear in the 5 years prior to the survey & $58(52 \%-64 \%)$ & $52 \%(43 \%-61 \%)$ & $54 \%(46 \%-62 \%)$ \\
\hline Breast examination in the 5 years prior to the survey & not available & $47 \%(39 \%-56 \%)$ & $43 \%(35 \%-51 \%)$ \\
\hline \multicolumn{4}{|l|}{ Service use: } \\
\hline Used hospital service in the 12 months prior to the survey & $25 \%(22 \%-28 \%)$ & $33 \%(30 \%-66 \%)$ & $24 \%(20 \%-29 \%)$ \\
\hline Attended their GP in the 12 months prior to the survey & $38 \%(33 \%-43 \%)$ & $57 \%(54 \%-60 \%)$ & $47 \%(42 \%-51 \%)$ \\
\hline Visited dentist in the 12 months prior to the survey & $15 \%(11 \%-18 \%)$ & $12 \%(10 \%-14 \%)$ & $12 \%(9 \%-15 \%)$ \\
\hline On waiting list for health care at the time of the survey & $4 \%(3 \%-5 \%)$ & $6 \%(5 \%-8 \%)$ & $4 \%(2 \%-5 \%)$ \\
\hline \multicolumn{4}{|l|}{ Identification of services needed $t$} \\
\hline Improve out of hours GP care & $52 \%$ & $35 \%$ & $52 \%$ \\
\hline Improve services for elderly & Not identified & $36 \%$ & $37 \%$ \\
\hline Social work services & Not identified & Not identified & $25 \%$ \\
\hline Services for teenagers & $19 \%$ & $21 \%$ & $14 \%$ \\
\hline Local maternity service & $47 \%$ & Not identified & Not identified \\
\hline Health promotion clinics & $24 \%$ & $31 \%$ & $12 \%$ \\
\hline
\end{tabular}

* $95 \%$ confidence intervals were calculated for the main outcome measures adjusting for strata (deprivation level), primary sampling unit (clusters) and weight (for Finglas only).

$\dagger 95 \%$ confidence intervals were not calculated for the respondents' reported health needs.

parallel qualitative analysis of the health service providers' perspective in the second two surveys $[7,8]$ provided more in-depth analysis of the health care services and indicated that the health service providers have a vast knowledge of the areas in which they work. Additional qualitative research involving community representatives would provide a greater depth of understanding of the inter-relationship between health needs and health care delivery needs and enable an exploration of the relationship between expectations and actual service provision.

\section{Community participation}

The communities were consulted and encouraged to participate throughout the process. For two to three months prior to each survey, the lead researcher informed key individuals, community groups and service providers 
This method requires:

- a rough es timate of the population in each small geographical area

- a calculation of a sample size for the outcome of interest using a single proportion formula and including a factor to adjust for design effect

- a two-stage sample selection method u sing cluster sampling to select the small geographical areas and random sampling to select the first household within the selected areas; replacement of absentee households with the next household in the sequence

- thirty clusters were considered to be an adequate number

- basic analysis guidelines depending on the main outcome of interest, e.g proportion with chronic disease or vaccination coverage

The limitations of the method were:

- population of interest should be relatively homogeneou s with respect to the main outcome

- the choice of thirty clusters as an adequate number was based on tradition rather than exact science

- sub-analysis by cluster or groups of clusters is unreliable

The que stionnaire dealt with the population and disease profile of developing coun tries, that is, infectious diseases and $m$ aternal health issues.

The survey was one of several methods recommended and encouraged the compilation and comparison of information from a variety of sources (triangulation).

\section{Figure I}

Features of model developed by the World Health Organisation, the Center for Disease Control and the Primary Health Care Management Advancement Programme to assess community health needs and service coverage $[1,4,5]$. 
The adaptations and their rationale were:

- the population was not homogeneous with respect to deprivation. We controlled for the two levels of deprivation by calculating separate samples for the less deprived and more deprived areas in each survey

- approximately $90 \%$ of households are registered in each electoral division. In order to ensure a more complete sample we adap ted the original cluster sampling methodology:

- households in each level of deprivation group were listed as per the electoral register and partitioned into clusters, each of seven households.

0 the first cluster in both the less deprived and more deprived areas was randomly selected and thereafter a systematic sample of clusters was selected using a pre-calculated sampling interval.

- a systematic sample of clusters, proportional to the number of households in each contributing district electoral division, was then selected; 30 clusters from the high deprivation group of district electoral divisions and 30 clusters from the low deprivation group of district electoral divisions.

- Each cluster consisted of seven adjacent houses. The researcher adjusted each cluster of seven adjacent houses and inserted those house s missing from the numerical sequence (in order to include those not on the electoral register).

- The researcher then removed from the end of the sequence the number of households in excess of seven.

- The que stionnaire was adapted to a degenerative and chronic disease model to reflect the morbidity and mortality patterns of a developed country 
Table 2: Time required to conduct surveys, and costs in Euro

\begin{tabular}{llll}
\hline & $\begin{array}{l}\text { First survey } \\
\text { (Tallaght) }\end{array}$ & $\begin{array}{l}\text { Second survey } \\
\text { (Docklands) }\end{array}$ & $\begin{array}{l}\text { Third survey } \\
\text { (Finglas) }\end{array}$ \\
\hline Time from design to publication & $\begin{array}{l}\text { April 200I to March } \\
2002 \\
\text { (II months) }\end{array}$ & $\begin{array}{l}\text { June 200I to September } \\
2002 \\
\text { (15 months) }\end{array}$ & $\begin{array}{l}\text { Nov 200I to February } \\
2003 \\
\text { (I5 months) }\end{array}$ \\
\hline Total expenditure in Euro & 32,771 & 96,026 & 91,068 \\
\hline
\end{tabular}

about the proposed survey and elicited their perceived needs. In each area, several health and social services needs were identified and included in the final survey questionnaires. In addition, local community members were trained and used as data collectors.

It is argued that community participation is an essential component of health needs assessment and that it should be a cyclical and iterative process in order to ensure sustainability [10]. However, sustainability is difficult as participating community data collectors are upskilled and may move on into regular paid employment. Those remaining in community work reported improved insights into local problems thus benefiting their communities.

The importance of feeding results back to the community has been previously emphasized [12]. The assessment reports were launched in public venues. We invited elected public and health board representatives, local service providers, community members and representatives of the charitable foundations involved. The community data collectors played an important role in ensuring that the wider community was aware of the launch. They actively participated in the launch by presenting their perspective on the assessments. Following the second and third assessments, summary posters were designed and placed in public areas throughout each community.

\section{Cost analysis}

The time required to conduct each study and the cost in Euro (2001) are presented in Table 2. The cost shown for the first survey is an under-estimate as the funding did not cover the full salary costs of the lead researcher. The subsequent surveys were fully funded and allowed for a more comprehensive needs assessment including qualitative interviews with local service providers. The additional resources also allowed for wider dissemination of results, with the production of the summary posters. When compared with the cost of surveillance systems, these surveys represent good value for money. However, the addition of a qualitative component to the second and third surveys incurred an additional time and monetary cost.

\section{Impact of reports on services}

The reports have been used by local healthcare providers, to lobby the health boards for more services, such as community antenatal clinics and a community paediatrician. The charitable foundation that commissioned the second assessment is now working with the local health board to provide a new primary healthcare centre. While it is not possible to prove conclusively that these service developments occurred solely as a result of the assessments, in each area the reports formed part of a process that directed changes in service delivery.

\section{Discussion}

Health assessment must be practical [13] and the model we have adapted was feasible and had the advantage of encouraging community involvement. The sampling method ensured genuine representation of all community members and minimized the potential bias inherent in focusing on the priorities of more vocal minorities.

\section{Health needs assessment as part of the planning cycle}

A favourable political environment has been described as a key component of successful health needs assessment [14]. For the two initial assessments [6,7], while the local health board approved the exercise, they had no direct role and consequently no ownership of the process. However, the first report led to another health board in Dublin commissioning the third assessment [8], which is being used to develop new services in this area. While local politicians and health board managers were briefly interested at the launch of the first report, they have not engaged further on the issues identified, which included lack of services and high levels of morbidity. By the time the third assessment was underway the environment had developed sufficiently to permit local health board involvement. As a result, the final assessment is genuinely part of the planning cycle [15] within that health board area, which has the statutory responsibility and capacity to deliver on the needs identified.

\section{Roles of participants in the process}

Local general practitioners and other healthcare providers were involved in all three assessments although previous 
reports have indicated that they do not see it as part of their core activities [16].

The role of charities in identifying need is worthy, but can raise expectations which they may have no remit to address. However, the commitment of the charity involved in the second report to building a new health centre in partnership with the local health board indicates that addressing needs identified can be part of the process even for non-governmental agencies without statutory responsibility to deliver services.

The role of academic departments in the health needs assessment process might also be questioned. The charities involved perceived the department in Trinity College to be objective and unaligned with service planners and providers. Academic departments possess the expertise and capacity to carry out assessments, but might better serve the process and the communities themselves by passing on these skills. Although this would lengthen the process and increase costs initially, it would be cost efficient in the future. Issues relating to sustainability and ownership of the process arise in health services research in general and the need for linkage and exchange between planners and researchers has been highlighted [17].

\section{Conclusion}

Our experience of using and adapting this health assessment methodology indicates the significant benefits for those seeking to carry out high quality health needs assessments in developed countries if they are prepared to learn from the experiences of developing country researchers. The adaptation of this methodology has provided more robust assessments that can be used by community members and service providers.

\section{Competing interests}

The author(s) declare that they have no competing interests.

\section{Authors' contributions}

SS, JL, TOD, JD and DH conceived of this paper. SS wrote the initial draft and co-ordinated the production of the paper with the other authors. JL conceived the methods for the needs assessment and performed the additional statistical analysis for this paper. JL, JD, FO'K, DH and TO'D contributed to the three reports on which this paper is based. All authors contributed to the drafting of this manuscript and read and approved the final paper.

\section{References}

I. Lemeshow S, Robinson D: Surveys to measure programme coverage and impact: a review of the methodology used by the expanded programme on immunization. World Health Stat $Q$ 1985, 38:65-75.
2. Anker M: Epidemiological and statistical methods for rapid health assessment: introduction. World Health Stat $Q$ 1991, 44:94-106.

3. Murray SA: Experiences with rapid appraisal in primary care: involving the public in assessing health needs, orienting staff and educating medical students. BMJ 1999, 3 I 8:440-444.

4. Rothenberg RB, Lobanov A, Singh KB, Stroh G: Observations on the application of EPI cluster survey methods for estimating disease incidence. Bull World Health Organ 1985, 63(1):93-99.

5. Primary Healthcare Management Advancement Programme: Assessing Community Health Needs and Coverage. Geneva: Aga Khan Foundation; 1993.

6. Department of Community Health and General Practice*: People living in Tallaght and their Health, A community based cross-sectional survey. 2002 [http://www.tcd.ie/ Community Health/Tallaght.pdf]. Dublin: Trinity College [*The Department of Community Health and General Practice in Trinity College Dublin has since been renamed as the Department of Public Health and Primary Care]

7. Department of Community Health and General Practice*: People living in the Dublin Docklands and their Health. 2002 [http:// www.tcd.ie/Community Health/Docklands.pdf]. Dublin: Trinity College [*The Department of Community Health and General Practice in Trinity College Dublin has since been renamed as the Department of Public Health and Primary Care]

8. Department of Community Health and General Practice*: People living in Finglas and their Health. 2003 [http://www.tcd.ie/ Community Health/Finglas.pdf]. Dublin: Trinity College [*The Department of Community Health and General Practice in Trinity College Dublin has since been renamed as the Department of Public Health and Primary Care]

9. Lwanga SK, Lemeshow S: Sample Size Determination in Health Studies: A Practical Manual. Geneva: World Health Organization; |991.

10. Israel B, Schulz A, Parker E, Becker B: Review of communitybased research: Assessing partnership approaches to improve public health. Annu Rev Public Health 1998, 19:173-202.

11. Stevens A, Gillam S: Needs assessment: from theory to practice. BM] 1998, 316: |448-1452.

12. McCaulay A, Commanda L, Freeman W, Gibson N, McCabe M, Robbins $C$, Twohig P: Participatory research maximises community and lay involvement. BMJ 1999, 319:774-778.

13. Wilkinson J, Murray SA: Assessment in primary care: practical issues and possible approaches. BMJ 1998, 316:1524-1528.

14. Jordan J, Wright J, Ayres P, Hawkings M, Thomson R, Wilkinson J, Williams R: Health needs assessment and needs-led health service change: a survey of projects involving public health doctors. J Health Serv Res Policy 2002, 7(2):7I-80.

15. Wright J, Williams R, Wilkinson JR: Development and importance of health needs assessment. $B M]$ | 998, 3 | 6 (7 | 40): I 3 | 0-3.

16. Hanlon P, Murie J, Gregan J, McEwen J, Moir D, Russell E: A study to determine how needs assessment is being used to improve health. Public Health 1998, I I 2(5):343-6.

17. Dash P, Gowman N, Traynor M: Increasing the impact of health services research. BMJ 2003, 327:1339-1341.

\section{Pre-publication history}

The pre-publication history for this paper can be accessed here:

http://www.biomedcentral.com/1472-6963/5/32/prepub 